\title{
Future Directions for Practice-Based Research Networks (PBRNs): A CERA Survey
}

\author{
Juliann Binienda, PhD, Anne Victoria Neale, PhD, MPH, \\ and Lorraine $S$. Wallace, $\mathrm{PhD}$
}

Background: Thought leaders from family medicine and practice-based research networks (PBRNs) have put forth definitions and goals recommending future directions for PBRNs. Evidence demonstrating that PBRNs are acting in accordance with these trends supports future investment in PBRN infrastructure, funding, and training of clinician researchers. Our objective was to explore the alignment of PBRN research efforts with thought leader recommendations.

Methods: The 2017 Council of Academic Family Medicine Educational Research Alliance surveyed PBRN directors via emails to 126 respondents. This survey included 6 general background questions about PBRN characteristics. An additional 25 questions focused on current and future research directions, including the training of health care professionals about PBRN research.

Results: The survey response rate was 56/126 (44\%). Physician faculty receive continuing medical education credit for PBRN training (reported by 12/56 of PBRN directors). PBRN provided continuing medical education for study participation $(24 / 56)$, reviewing study results $(7 / 56)$, attending a study results presentation (24/56), and attending study planning meetings (13/56). Practice-based research education of medical students and residents was reported at 11/56 and 14/56, respectively. Current PBRN research efforts were most frequent in the areas of community engagement, practice transformation, and quality improvement projects.

Conclusion: PBRNs currently thrive on conducting research predominantly in quality improvement and practice transformation. However, the study findings suggest that moving forward, PBRNs should participate more in training the future generations of primary care researchers and to address health policy needs. (J Am Board Fam Med 2018;31:917-923.)

Keywords: Continuing Medical Education, Family Physicians, Goals, Health Policy, Primary Health Care, Quality Improvement, Research Personnel, Social Responsibility

Primary care practice-based research networks (PBRNs) are learning communities of ambulatory care practices that share a common interest in building an evidence base for primary care. ${ }^{1}$ The earliest PBRNs were organized in the 1970s and provided important observations on the natural his-

This article was externally peer reviewed.

Submitted 1 March 2018; revised 15 June 2018; accepted 19 June 2018.

From Department of Family Medicine and Public Health Sciences, Wayne State University, Detroit, MI (JB, AVN); Health Services Management and Policy, College of Medicine, The Ohio State University, Columbus, OH (LSW).

Funding: none.

Conflict of interest: none declared.

Corresponding author: Juliann Binienda, PhD, Department of Family Medicine and Public Health Sciences, Wayne State University, Detroit, MI 48201 (E-mail: jbinien@med.wayne.edu). tory of primary care health concerns. ${ }^{2}$ The landscape of PBRNs has diversified, and while some networks continue to focus on patient-oriented outcomes that matter, others specialize in improving the delivery of care and quality improvement (QI) and promoting models of practice facilitation and components of the patient-centered medical home. In 2011, Williams and Rhyne ${ }^{3}$ argued that PBRNs have moved beyond patient illness studies and practice improvement projects, stating that they commonly embraced a spectrum of activities related to patient care, community health improvement, and patient and community engagement (CE). This occurred predominately because of the growing numbers of PBRNs and with accompanying increases in sophisticated research practices. 
Building the pipeline of investigators with the knowledge and skills necessary to conduct research in busy, decentralized clinical practices is important for sustaining progress made by the current generation of primary care researchers. Although some networks provide excellent mentoring to the younger generation of primary care investigators, ${ }^{4}$ the growing diversity of PBRN's mission and vision makes generalizing about PBRNs difficult.

There have been suggestions for PBRNs to focus on recent primary care initiatives, such as involving patients and community members in research efforts, providing continuing medical education (CME) to clinicians who practice practice-based research (PBR), and increasing the diversity of clinician researchers. A number of recent articles have exhorted our small PBRN community to build interdisciplinary alliances to emphasize how primary care is key to improving the health of our nation. As examples, Werner and Stange ${ }^{1}$ advocate that PBRNs should focus on the "Triple Aim" of improving patients' experiences of health care, improving the health of populations, and reducing the per capita cost of health care. ${ }^{5}$ Westfall et $\mathrm{al}^{6}$ suggest that PBR is a form of CE but does not specify the definition of CE. Williams and Rhyne ${ }^{3}$ posit that PBRN members learn from their research engagement and, therefore, that CME credits should be provided for members participating in studies, including reviewing results, attending presentations of the application of those results, and assisting in planning future studies. Other forms of CE include PBRN partnerships with diverse organizations, including public health departments, schools, patient advocacy groups, and nonprofit social service organizations. ${ }^{1}$ In 2014, Spears et $\mathrm{al}^{7}$ reported on a national survey of PBRN directors (63\% response rate) regarding CE strategies aimed at recruiting diverse groups into studies. Perhaps it is not surprising that PBRNs implementing engagement strategies when working with clinic and community partners also report less difficulty in recruiting diverse populations. $^{7}$

In 2016, Gaglioti et $\mathrm{al}^{4}$ advocated for a survey of PBRN directors that would detail existing relationships with stakeholders in government/public health, policymaking, and funding arenas. The goal is to build long-term relationships with funder, leader, and policy maker stakeholders that would then enable improved visibility and understanding of the potential of PBRNs to fulfill the need for research with complex patients in communitybased settings. ${ }^{4,8}$ These new collaborations could also lead to new funding streams as well.

Here, we report a survey of PBRN directors that captures vision, scope, and future directions. Going beyond the surveys of the past that described attributes such as membership, funding sources, and publications, our objective was to explore the extent to which PBRNs are aligning with family medicine thought leaders.

\section{Methods}

\section{Sampling Frame and Data Collection Procedures}

The survey sampling frame was composed of family medicine/primary care PBRN directors from the Agency for Healthcare Research and Quality registry (https://pbrn.ahrq.gov/pbrn-registry). In addition, self-identified directors from the 2017 North American Primary Care Research Group Practice-based Research Network Conference were also included, for an initial sampling frame of 130 PBRN directors.

Of the 130 PBRN directors in the sampling frame, 2 had previously opted out of Council of Academic Family Medicine Educational Research Alliance (CERA) surveys, and, thus, the survey invitation was emailed to 128 individuals through Survey Monkey software. Five emails could not be delivered, and, of those, 4 valid emails were located and the survey invitation was resent. During the course of the survey, 3 directors were identified as no longer in that position and the new director was identified and sent a survey; this did not affect the sample size. In 1 case, the survey was sent to a director and codirector of the same PBRN; they completed only 1 survey, reducing the sample size by 1 . In the end, the final sample frame included 126 PBRN directors. See the Appendix for the text of the emailed invitation to participants.

\section{Survey Questions}

The 31-item survey questions about PBRN research activities were adopted from previously published studies to examine similarities and differences. ${ }^{3,7}$ Six questions were part of a larger CERA omnibus survey. ${ }^{9}$ These questions explored PBRN characteristics (age, geographic scope, years of PBRN director tenure, and the numbers of practice locations, practitioner members, and residency sites). 
Eight questions examined current PBRN research activities, followed by 6 questions on the types of research foci planned over the next 3 years. These included CE, QI projects, surveillance, use of patient registries, and efforts toward health policy reform. Five questions addressed the aim of PBRN involvement in training physicians, from medical students and residents to practicing physician training in PBRN, including CME efforts. Two additional questions asked about research education and training for medical students and residents. Finally, 4 questions probed CME for various research-related activities (participating in studies, reviewing study results, attending presentations of the application of the results, or planning future studies).

The CERA steering committee evaluated questions for consistency with the overall subject aim, readability, and existing evidence of reliability and validity. Survey questions were pretested for flow, timing, and readability with a group of family medicine educators who were not part of the target population (PBRN directors), and modified based on pretesting feedback. Ethics approval was obtained from the American Academy of Family Physicians Institutional Review Board in October 2017. Data were collected from October to November 2017. After the initial invitation, 5 follow-up emails were sent to encourage nonrespondents to complete the survey. Fifty-six PBRN directors completed the survey, for an overall survey response rate of $44.4 \%$.

\section{Data Analyses}

Descriptive statistics (frequencies and percentages) were used to depict the characteristics of PBRNs in terms of current practices, future research efforts, and training of health care professionals. All data analyses were conducted using IBM SPSS Statistics for Windows version 25.0. ${ }^{10}$

\section{Results \\ PBRN Characteristics}

Table 1 shows descriptive data on the geographic scope and age of PBRNs, years the responding PBRN director has led the network, the number of practitioner members, and the numbers of member locations and affiliated residency sites. Our sample reported that their PBRN was most often local $(\mathrm{n}=18)$ or statewide $(\mathrm{n}=20)$. Ten
Table 1. Characteristics of Practice-based Research Networks That Participated in the CERA Survey, fall 2017; $(\mathrm{n}=56)^{*}$

\begin{tabular}{|c|c|c|}
\hline \multicolumn{2}{|l|}{ Survey Questions } & \multirow{2}{*}{$\frac{N(\%)}{18(32)}$} \\
\hline Geographic scope of PBRN & local & \\
\hline & state & $20(36)$ \\
\hline & regional & $13(23)$ \\
\hline & national & $5(9)$ \\
\hline \multirow[t]{5}{*}{ PBRN age } & $<1$ year & $1(2)$ \\
\hline & 1 to 3 years & $4(7)$ \\
\hline & 4 to 5 years & $6(11)$ \\
\hline & 6 to 10 years & $10(18)$ \\
\hline & $>10$ years & $35(62)$ \\
\hline \multirow{5}{*}{$\begin{array}{l}\text { Duration that PBRN director was } \\
\text { in current role }\end{array}$} & $<1$ year & $6(11)$ \\
\hline & 1 to 3 years & $14(26)$ \\
\hline & 4 to 5 years & $12(21)$ \\
\hline & 6 to 10 years & $10(18)$ \\
\hline & $>10$ years & $13(24)$ \\
\hline \multirow{3}{*}{$\begin{array}{l}\text { No. of active practitioners in } \\
\text { PBRN }\end{array}$} & 1 to 20 & $9(16)$ \\
\hline & 21 to 49 & $10(18)$ \\
\hline & $>49$ & $35(66)$ \\
\hline \multirow{4}{*}{$\begin{array}{l}\text { No. of practice locations } \\
\text { comprising the PBRN }\end{array}$} & $<5$ & $1(2)$ \\
\hline & 5 to 9 & $3(5)$ \\
\hline & 10 to 19 & $11(20)$ \\
\hline & $>19$ & $41(73)$ \\
\hline \multirow{5}{*}{$\begin{array}{l}\text { No. of residencies affiliated with } \\
\text { the PBRN }\end{array}$} & 0 & $11(20)$ \\
\hline & 1 to 3 & $27(48)$ \\
\hline & 4 to 18 & $15(26)$ \\
\hline & 19 to 24 & $0(0)$ \\
\hline & $>24$ & $2(4)$ \\
\hline
\end{tabular}

${ }^{*}$ Due to missing data, the $\mathrm{N}$ responding varies by question. PBRN, practice-based research networks.

PBRNs were 6 to 10 years of age, and 35 PBRNs were established more than 10 years ago. A majority of PBRN directors (35/56) held their leadership tenure for $\geq 6$ years. Regarding the number of active practitioners in the PBRN, 35 directors reported $\geq 50$, and 41 reported $\geq 20$ practitioners in their PBRN. The number of PBRN-affiliated residency sites ranged from 0 to 25 sites. Fifteen directors reported affiliations with 4 to 18 residency sites and 2 with affiliations with 25 residency sites. Eleven PBRNs were not affiliated with a primary care residency.

\section{PBRN Research Education and Training}

Table 2 shows results to questions about whether students and residents receive any training in PBR, and then if the PBRN is involved in any research education and training for different learner groups 
Table 2. Affirmative Responses to Practice-based Research Network Education and Research Training Activities*

\begin{tabular}{|c|c|}
\hline Question & $\mathrm{N}(\%)$ \\
\hline $\begin{array}{l}\text { Our medical students receive training on practice- } \\
\text { based research methods. }\end{array}$ & $11(20)$ \\
\hline $\begin{array}{l}\text { Our medical students engage in PBRN research } \\
\text { projects. }\end{array}$ & $25(45)$ \\
\hline Our PBRN provides training for medical students. & $20(36)$ \\
\hline $\begin{array}{l}\text { Residents in our program receive training in } \mathrm{PBR} \\
\text { methods. }\end{array}$ & $14(25)$ \\
\hline $\begin{array}{l}\text { Residents in our program engage in PBRN } \\
\text { research projects. }\end{array}$ & $26(47)$ \\
\hline $\begin{array}{l}\text { Our PBRN provides training for our medical } \\
\text { residents. }\end{array}$ & $22(41)$ \\
\hline $\begin{array}{l}\text { Our faculty receive CME training in PBR } \\
\text { methods. }\end{array}$ & $12(22)$ \\
\hline \multicolumn{2}{|l|}{$\begin{array}{l}\text { Faculty receive CME for PBRN-related activities } \\
\text { for: }\end{array}$} \\
\hline study participation & $24(44)$ \\
\hline reviewing study results & $7(13)$ \\
\hline attending presentations of results & $24(44)$ \\
\hline planning future studies & $13(24)$ \\
\hline
\end{tabular}

${ }^{*}$ Due to missing data, the $\mathrm{N}$ responding varies by question. CME, continuing medical education; PBR, practice-based research; PBRN, practice-based research networks.

(medical students, residents, and physicians). Medical students (11/56) and residents (14/56) receive a minimal amount of formal curricular training in PBR methods (by anyone.) Just less than half reported that their PBRN faculty provided training for medical students (20/56) or residents (22/56) Medical student participation in PBR research was reported by $25 / 56$ and resident participation was reported by $26 / 56$ directors. When asked about physician faculty receiving CME credit for PBRN training or involvement, 12/56 responded affirmatively. In addition, PBRNs provide CME for study participation (24/56), reviewing study results (7/ 56 ), attending a presentation about study results (24/56), and for attending meetings to plan future studies $(13 / 56)$.

\section{PBRN Current and Future Research Efforts}

Table 3 shows results regarding current PBRN research efforts and plans to engage in these topic areas in the future. Engaging with community stakeholders and practice transformation were the largest current research foci: 48/56 for CE and $46 / 56$ for practice transformation. A majority reported future intentions to focus on CE (46/56) or practice transformation (39/56). PBRNs frequently participate in QI projects, with 42/56 reporting single-site QI projects and 38 engaged in multisite QI projects; 42 reported future QI plans. Thirtyfive PBRNs reported the current use of patient registries for research purposes, and 39 PBRNs plan future use. Regarding PBRN research linking clinical practice to health policy, 25/56 were engaged in this area, although 32 expressed interest in doing more in the future. Over half $(32 / 56)$ had contributed data to surveillance projects.

\section{Discussion}

Similar to previous descriptive survey data, the majority of responding PBRNs were established more than 5 years ago, ${ }^{7}$ indicating an opportunity for such established networks to examine their past/ current research endeavors and develop strategic

Table 3. Affirmative Responses for Practice-based Research Network Current and Projected (future) Research Efforts $(\mathrm{n}=56)^{*}$

\begin{tabular}{llr}
\hline Questions & Current & Future \\
\hline Engaged with community stakeholders in research efforts. & $48(87)$ & N (\%) \\
Contributed data to epidemiologic surveillance projects. & $18(33)$ & $46(84)$ \\
Conducted research using patient registries. & $35(64)$ & $14(26)$ \\
Conducted QI for local practice sites. & $42(76)$ & $39(71)$ \\
Conducted QI for multiple practice sites. & $38(69)$ & $4 *$ \\
Conducted research projects to facilitate practice transformation. & $46(84)$ & $32(76)$ \\
Conducted research linking clinical work with health policy reform efforts. & $25(45)$ & $32(58)$ \\
Conducted research transitioning to PCMH. & $33(60)$ & $* *$ \\
\hline
\end{tabular}

* Due to missing data, the $\mathrm{N}$ responding varies by question.

${ }^{* *}$ Future plans to conduct research in this area were not asked.

$\mathrm{PCMH}$, patient-centered medical home; QI, quality improvement. 
plans for the future. In our survey, 20/56 of the PBRNs have newer directors of less than 5 years. This creates a challenge in terms of the continuity of research and study planning.

The data from this survey suggest that PBRNs have modestly responded to thought leaders' vision for the future with respect to providing CME for an array of activities. Williams \& Rhyne $^{3}$ in 2011 suggested that offering CME for a range of PBRN experiences would increase physician involvement. However, our survey data suggest that less than half of the survey respondents noted offering any type of CME for a variety of PBRN activities. In 2010, National Academy of Medicine (formerly the Institute of Medicine) reported on CME activities. ${ }^{11}$ This report urged CME providers to incorporate need assessments and provide interactive, stimulating programs such as online videos or virtual reality procedural trainings, which link directly to clinical care. To sustain the pipeline of primary care practitioners and researchers, PBRNs should explore the best CME methodology and incentives to enhance education and training of all health care professionals. PBRNs are encouraged to critically evaluate their current $\mathrm{CME}$ offerings and consider the optimal methods and best practices to enhance PBR practice.

A majority of PBRNs $(n=45)$ have some contact with their residency training sites. This involvement or connection to postgraduate training sites is a positive sign that PBRNs are, at a minimum, introducing PBR methods to physician trainees. PBRN directors indicated that medical students and residents are often involved in PBRN research projects, yet they also indicate that these learners are receiving minimal formalized education in PBR methodology. This offers PBRNs the opportunity to provide more research exposures and mentorship to the next generation of primary care researchers. The low rate of PBRNs providing training in PBR method training is consistent with results from Peterson et al. ${ }^{12}$ Perhaps the definition of PBR varies based on the individual PBRN culture and focus. The lack of PBRN involvement in direct teaching may be indicative of the separation between the scientist and the educator.

As Westfall et $\mathrm{al}^{6}$ noted, CE reporting rates by PBRNs are quite variable, possibly due to lack of a common definition. Tierney et $\mathrm{al}^{13}$ reported that $40 \%$ of respondents to a 2003 survey noted community involvement a PBRN strength. In a 2010 survey by Peterson et al, ${ }^{12} 8 \%$ of PBRNs reported community participation as a strength, while $40 \%$ reported it a challenge. In a 2011 survey, Spears et $\mathrm{al}^{7}$ found community participation a strength for $28 \%$ of PBRNs, with $40 \%$ reporting it a challenge; strategies involving community partners on research teams and dissemination efforts were the least implemented. The respondents to our 2017 survey noted that engaging with community stakeholders is the most common research area (48/56) and a large majority have plans to continue this engagement in the future.

Our findings related to the high number of QI projects conducted by PBRNs, and the emphasis on practice transformation was not surprising. This suggests that PBRNs have responded to the call for primary care to lead the change in patient-centered clinical approaches to reduce health care costs and to boost the quality of patient health outcomes. ${ }^{14}$ In addition, our finding of a low level of PBRN engagement in clinically relevant and integrated health policy research indicates a need for exposure, training, and mentorship for this type of research. This finding also suggests only a slight progress related to Williams and Rhyne ${ }^{3}$ who advocated for the expansion of the definition of PBRNs to include the investigation of communitydriven research topics, which would ultimately lead to health policy change and improvement. Others have offered related solutions to this potential dilemma, such as using social media outlets for the dissemination of research results in laymen's terms. ${ }^{15}$

\section{Study Limitations}

The findings generated from this study should be considered within the context of several limitations. First, with a response rate of $44 \%$, the representativeness of the sample is unknown, and the results may not be generalizable to all PBRNs. Second, the cross-sectional nature of the study only provides a single snapshot in time, but our findings provide an important look at PBRNs in 2017. Third, the data from the survey questions reported here were part of a larger CERA questionnaire, and so the number of questions we could ask to address our particular aims were limited. Thus, due to the brief nature of the survey, not all terms were defined, and we cannot be sure that all respondents had a common understanding of content (eg, CE or health policy 
advocacy). For example, does CE require a community advisory board? This may also be true for practice transformation efforts and patient registries; is an electronic medical record the only type of patient registry? Fourth, the reliability of future intentions is difficult to ascertain, and there could be a tendency by the respondent to report desires that are well-intentioned but, because of low resources, are unlikely to come to fruition.

\section{Conclusion}

Although PBRNs continue to thrive and make efforts toward responding to health care research trends, there are ongoing struggles in terms of training health care providers about PBR and the role of the networks to link clinical research for optimum patient and community health outcomes. These results may support recommendations for future directions, such as providing innovative CME activities, creating training for health policy advocacy and research efforts, and strategic planning by PBRN director leadership. Moving forward, we suggest that PBRNs should consider taking on the role of network facilitators by engaging with leaders of academic health centers/medical schools, disciplinary leadership, and/or well-positioned community, government, or public health officials. In 2006, Green and Hickner $^{2}$ noted that PBRNs had set sail. We hope that PBRNs continue to sail forward, not only navigating the safer passages but also assuming leadership and taking risks to travel those waters that are yet unexplored.

The authors thank the PBRN directors who completed the survey and Society of Teachers of Family Medicine CERA for their support of this study.

To see this article online, please go to: bttp://jabfm.org/content/ 31/6/917.full.

\section{References}

1. Werner JJ, Stange KC. Praxis-based research networks: an emerging paradigm for research that is rigorous, relevant, and inclusive. J Am Board Fam Med 2014;27:730-5.

2. Green LA, Hickner J. A short history of primary care practice-based research networks: from concept to essential research laboratories. J Am Board Fam Med 2006;19:1-10.
3. Williams RL, Rhyne RL. No longer simply a PBRN: health improvement networks. J Am Board Fam Med 2011;24:485-8.

4. Gaglioti AH, Werner JJ, Rust G, Fagnan LJ, Neale AV. PBRNs bridging the gaps between communities, funders, and policymakers. J Am Board Fam Med 2016;29:630-5.

5. Berwick DM, Nolan TW, Whittington J. The triple aim: care, health and cost. Health Aff (Millwood) 2008;27:759-69.

6. Westfall JM, Fagnan LJ, Handley M, et al. Practicebased research is community engagement. J Am Board Fam Med 2009;22:423-7.

7. Spears W, Tsoh JY, Potter MB, et al. Use of community engagement strategies to increase research participation in practice-based research networks (PBRNs). J Am Board Fam Med 2014;27:763-71.

8. Hickner J, Green LA. Practice-based research networks (PBRNs) in the United States: growing and still going after all these years. J Am Board Fam Med 2015;28:541-5.

9. Shokar N, Bergus G, Bazemore A, et al. Calling all scholars to the council of academic family medicine educational research alliance (CERA). Ann Fam Med 2011;9:372-3.

10. IBM Corp. IBM SPSS Statistics for Windows, Version 25.0. Armonk NY. IBM Corp. Released 2017.

11. Institute of Medicine. Redesigning continuing education in the health professions. Washington, DC: The National Academies Press; 2010.

12. Peterson K, Lipman PD, Lange C, Cohen R, Durako $\mathrm{S}$. Supporting better science in primary care: a description of practice-based research networks (PBRNs) in 2011. J Am Board Fam Med 2012;25:565-71.

13. Tierney W, Oppenheimer C, Hudson B et al. A national survey of primary care practice-based research networks. Ann Fam Med 2007;5:242-50.

14. Crabtree B, Nutting $P$, Miller $W$, et al. Primary care transformation is hard work: Insights from a 15-year developmental program of research. Med Care December 2011;49:S28-S35.

15. Krzyzanowska MK, Kaplan R, Sullivan R. How may clinical research improve healthcare outcomes? Ann Oncol 2011;22:vii10-vii15.

\section{Appendix. Text of email to all PBRN directors:} Dear Dr. X,

The Association of Departments of Family Medicine (ADFM), Society of Teachers of Family Medicine (STFM), Association of Family Medicine Residency Directors (AFMRD), and North American Primary Care Research Group (NAPCRG) would appreciate your response to this survey of directors of practice based research networks (PBRN). 
The survey should take about 15 minutes to complete.

[Insert survey link here]

The results of this survey will be used in published research, so it is important that all PBRN directors complete the survey. The data will also be added to a clearinghouse that you and other academic family medicine faculty can use to develop new research ideas or to answer administrative questions. This information will be stripped of any identifiers linking the data back to you or your PBRN.

Your response is important; each completed survey improves the accuracy and representativeness of the data. 